mạch của khối u, tình trạng di căn phổi.

- Chưa thây có mối liên quan có ý nghĩa giữa

giá trị shunt gan-phổi và đáp ứng với SIRT.

\section{TÀI LIÊU THAM KHẢO}

1. Andreas HM, Carlo S, Geert M, et al (2013). Standards of Practice in Transarterial Radioembolization. CardioVascular and Interventional Radiology volume 36, pages613-622.

2. Dainel TM (2018). Spectrum of findings in 99mTC-MAA SPECT/CT and their significance in treatment planning for Yttrium 90-microsphere radioembolization for hepatocellular carcinoma. Nucl Med Biomed Imaging, Volume 3(1): 1-4.

3. Lewandowski RJ, Kulik LM, et al (2009). A Comparative Analysis of Transarterial Downstaging for Hepatocellular Carcinoma: Chemoembolization Versus Radioembolization. American Journal of Transplantation, Vol. 9: 1920-1928.

4. Joseph RK, Ahmed G, Ryan H, et al (2017). Indicators of Lung Shunt Fraction Determined by Technetium-99 m Macroaggregated Albumin in
Patients with Hepatocellular Carcinoma. CardioVascular and Interventional Radiology, Vol. 40: 1213-1222.

5. Ron CG, Sean PZ, et al (2014). Characteristics of primary and secondary hepatic malignancies associated with hepatopulmonary shunting. Radiology, Vol. 271(2):602-612.

6. Rania R, Mohammed SH (2014). The relationship between the percentage of lung shunting on Tc-99m macroaggregated albumin (Tc-99m MAA) scan and the grade of hepatocellular carcinoma vascularity. The Egyptian Journal of Radiology and Nuclear Medicine, Vol. 45: 333-342.

7. Tyler S, Daneil D, et al (2016). Elevated Lung Shunt Fraction as a Prognostic Indicator for Disease Progression and Metastasis in Hepatocellular Carcinoma. J Vasc Interv Radiol, Vol. 27(6):804-11.

8. Minzhi $X$, Steven $L$, et al (2016). $90 Y$ Radioembolization Lung Shunt Fraction in Primary and Metastatic Liver Cancer as a Biomarker for Survival. Clin Nucl Med, Vol. 41(1):21-7.

\title{
KẾT QUẢ ĐIỀU TRỊ BƯớC ĐẦU 02 CA LÂM SÀNG U NGUYÊN BÀO THẦN KINH KHỨU GIÁC TẠI BỆNH VIỆN K
}

\section{TÓM TẮT}

Mục tiêu: Mô tả đặc điểm lâm sàng, cận lâm sàng và kết quả điều trị bước đầu của 02 ca bệnh u nguyên bào thần kinh khứu giác với phương pháp điêu trị phẫu thuật kết hợp hóa xạ trị đồng thời tại Bệnh viện K. Đối tượng và phương pháp: Nghiên cứu mô tả cắt ngang, báo cáo chùm ca bệnh trên 02 người bệnh với cách chọn mẫu thuận tiện. Thời gian từ tháng 10/2020 đến tháng 10/2021. Kết quả: Hai người bệnh nam, 44 tuổi và 50 tuổi. Triệu chứng lâm sàng chính của người bệnh ngat tắc mũi một bên, chảy máu mũi một bên, đau nửa đầu. Kết quả cận lâm sàng phù hợp với y văn miêu tả bệnh. Kết quả điều trị đáp ứng hoàn toàn và không có biến chứng trên hệ tạo huyết, với phương pháp điêu trị phẫu thuật kết hợp hóa xạ trị trị đồng thời hậu phẫu liều 60Gy/30fx và hóa chất Cisplatin $100 \mathrm{mg} / \mathrm{m}^{2}$ đa chu kỳ 3 tuần. Kết luận: Phương pháp điêu trị phẫu thuật kết hợp hóa xạ trị đồng thời hậu phẫu bước đâu có hiệu quả tốt trên nhóm người bệnh này.

Tư khóa: U nguyên bào thân kinh khứu giác; Bệnh viện K.

\section{SUMMARY}

\section{THE INITIAL TREATMENT RESULTS OF}

\section{*Bênh viện $K$}

Chịu trách nhiệm chính: Vũ Việt Anh

Email: anhvubvk@gmail.com

Ngày nhận bài: 10.9.2021

Ngày phản biện khoa học: 10.11.2021

Ngày duyệt bài: 16.11.2021

\section{TWO ESTHESIONEUROBLASTOMA CLINICAL CASES AT THE NATIONAL CANCER HOSPITAL}

Objectives: This study aimed at describing clinical, subclinical characteristics, and the initial result of treatment on two cases of olfactory neuroblastoma by surgical treatment combined with chemotherapy and radiotherapy at the National Cancer Hospital. Subjects and methods: The cross-sectional study and reporting a cluster of cases was conducted on two patients with a convenient sampling method. The period is from October 2020 to October 2021. Results: The sexes of the two patients were male, with ages 44 and 50 respectively. The main clinical symptoms of the patients were stuffy nose, one-sided nasal bleeding, migraine headache. The subclinical test results were consistent with the medical literature describing the disease. Applying surgical treatment method combining chemotherapy and radiation therapy at the same time after surgery, with a dose of $60 \mathrm{~Gy} / 30 \mathrm{fx}$ and chemical Cisplatin $100 \mathrm{mg} / \mathrm{m}^{2}$ for a 3 -week multi-cycle. Treatment results showed that two patients responded completely and had no complications on the hematopoietic system. Conclusion: The surgical treatment combined with chemotherapy and radiotherapy at the same time after surgery initially has a good effect on these patients.

Keywords: Esthesioneuroblastoma; National Cancer Hospital.

I. ĐẶT VẤN ĐỀ

U nguyên bào thần kinh khứu giác hay còn có tên khoa học là Esthesioneuroblastoma (ENB) là 
một u ác tính hiếm gặp, phát sinh từ biểu mô của thần kinh khứu giác. ENB chiếm khoảng $2 \%$ trong các loại u tại xoang mũi, với tỷ lệ mắc bệnh là 0,4 trên một triệu dân số ${ }^{1}$, và hẩu hết các bệnh nhân có độ tuổi từ 35 đến 70 tuổi ${ }^{2}$. Hiện tại, chưa có bằng chứng nào chỉ ra nguyên nhân và các yếu tố nguy cơ gây bệnh, người bệnh thường có các triệu chứng không đặc hiệu như ngạt mũi, đau đầu, và chảy máu cam. Chính vì các triệu chứng biểu hiện không đặc hiệu, giống với triệu chứng của viêm xoang mạn tính, việc chẩn đoán có thể bị trì hoãn trong thời gian dài, do đó bệnh nhân ENB thường được chẩn đoán ở giai đoạn muộn.

Vì tính hiếm gặp của bệnh, cho tới nay các nghiên cứu về ENB chủ yếu giới hạn bằng hình thức báo cáo ca bệnh riêng lẻ hoặc chùm ca bệnh được tiến hành tại nước ngoài, các ghi nhận tại Việt Nam còn ít. Xuất phát từ thực tế trên, chúng tôi tiến hành đề tài: "Kết quả điều trị bước đâu 02 ca lâm sàng u nguyên bào thần kinh khứu giác tại Bệnh viện $\mathrm{K}^{\prime \prime}$. Với 02 mục tiêu: (1) Mô tả đặc điểm lâm sàng, cận lâm sàng của 02 bệnh nhân u nguyên bào thần kinh khứu giác; (2) Mô tả kết quả điều trị bước đầu của 02 bệnh nhân u nguyên bào thần kinh khứu giác tại Bệnh viện $K$.

\section{II. ĐỐI TƯỢNG VÀ PHƯƠNG PHÁP NGHIÊN CỨU}

2.1. Đối tượng. 02 người bệnh được chẩn đoán mắc và điều trị bệnh u nguyên bào thần kinh khứu giác tại Bệnh viện $\mathrm{K}$, thời gian từ 10/2020 đến 10/2021.

2.2. Phương pháp nghiên cứu. Nghiên cứu mô tả cắt ngang, báo cáo chùm ca bệnh.

2.3. Cỡ mấu và cách chọn mẫu. Áp dụng phương pháp chọn mẫu thuận tiện.

2.4. Phương pháp thu thập số liệu. Điều tra viên là cán bộ y tế công tác tại Bệnh viện K, trực tiếp chăm sóc và điều trị cho người bệnh ENB, số liệu được thu thập từ hồ sơ bệnh án của người bệnh ENB qua các ca bệnh được chẩn đoán và điều trị tại bệnh viện trong thời gian nghiên cứu.

2.5. Xử lý số liệu. Số liệu được thu thập thông qua bệnh án nghiên cứu, nhập số liệu trền phần mềm excel, word và trình bày theo đặc điểm từng ca bệnh.

2.6. Biến số nghiên cứu. Nhóm biến số liên quan đến đặc điểm cá nhân của đối tượng nghiên cứu: Họ và tên, tuổi, giới, địa chỉ, liên lạc, ngày vào viện, ngày ra viện.

Nhóm biến số liên quan đến đặc điểm lâm sàng, cận lâm sàng của đối tượng nghiên cứu:
Lý do vào viên, kết quả $C T$, kết quả MRI.

Nhóm biến số liên quan đến kết quả điều trị bước đầu: Đáp ứng tại u, đáp ứng tại hạch, biến chứng trên hệ tạo huyết, biến chứng ngoài hệ tạo huyết.

2.7. Đạo đức nghiên cứu. Nghiên cứu được triển khai sau khi được Hội đồng thông qua đề cương của Bệnh viện $K$ phê duyệt. Đối tượng nghiên cứu được giải thích về mục đích của nghiên cứu trước khi tiến hành và chỉ thực hiện khi có sự chấp nhận hợp tác của đối tượng tham gia nghiên cứu. Số liệu, thông tin thu thập chì phục vụ cho mục đích nghiên cứu, không sử dụng mục đích nào khác.

\section{KẾT QUẢ NGHIÊN CỨU}

\section{1. Đăc điểm lâm sàng, cận lâm sàng}

*Bênh nhân 01. Bênh nhân nam, 44 tuổi, vào viển ngày $08 / 01 / 2021$. Bệnh nhân xuất hiện triệu chứng chảy máu mũi trái, ngạt mũi bên trái và đau nửa mặt trái xuất hiện trong vòng 1 tháng. Người bệnh đi khám và được chẩn đoán $\mathrm{K}$ xoang hàm trái với giai đoạn cT3N1MO (Kadish D) và phẫu thuật lấy u tại khoa Ngoại, Bệnh viện Tai Mũi Họng Trung Ương. Hình ảnh chụp cắt lớp vi tính (CT) sau phấu thuật cho thấy dày tạo khối vùng vòm trái ngấm thuốc manh sau tiêm hạch cảnh cao lệch trái. Kết quả mô bệnh học và hóa mô miễn dịch phù hợp với ENB.

*Bênh nhân 02. Bệnh nhân nam, 50 tuổi, vào viện ngày $06 / 11 / 2020$. Bệnh nhân có triệu chứng chảy máu cửa mũi trước trái, ngạt mũi trái và triệu chứng diễn biến từng đợt trong vòng 6 tháng trước khi nhập viện. Bệnh nhân được chẩn đoán ENB mũi trái giai đoạn T3NOMO (Kadish $\mathrm{B}$ ) và phẫu thuật lấy u hốc mũi trái tại Bệnh viện Tai Mũi Họng Trung Ương và chuyển viện qua Bệnh viện K3 tiếp tục điều trị. Kết quả mồ bệnh học cho kết quả u nguyên bào thần kinh khứu giác mũi trái. Kết quả cộng hưởng từ (MRI) hàm mặt kết hợp với siêu âm cho thây hình ảnh hạch nhỏ không đặc hiệu góc hàm trái, polyp xoang bướm và có dịch ở các xoang sọ mặt. Nghi ngờ tổn thương xương sọ mặt (kết quả xạ hình xương với MDP).

3.2. Kết quả điêu trị bước đâu. Cả hai người bệnh được điều trị hóa xạ đồng thời hậu phẫu $60 \mathrm{~Gy} / 30 \mathrm{fx}$ và hóa chất Cisplatin $100 \mathrm{mg} / \mathrm{m}^{2}$ đa chu kỳ 3 tuần. Kết quả điều trị cho thấy người bệnh đáp ứng hoàn toàn (khối u biến mất hoàn toàn kéo dài ít nhất 4 tuần và không xuất hiện tổn thương mới) và không có biến chứng trên hệ tạo huyết. 


\section{BÀN LUÂN}

Giống với hầu hết các bênh ác tính tại cấu trúc mũi, ENB không có triệu chứng đặc hiệu. Thời gian trung bình giữa sự xuất hiện của triệu chứng đầu tiên và chẩn đoán bệnh là 6 tháng. Các triệu chứng phổ biến nhất là tắc mũi một bên $(70,0 \%)$, sau đó là chảy máu cam $(46,0 \%)^{3}$. Tại nghiên cứu của chúng tôi trên 02 người bệnh, bệnh nhân thứ nhất có triệu chứng chính là chảy máu cam mũi trái, ngạt mũi bên trái và đau nửa mă̆t trái kéo dài 2 tháng với giai đoạn bênh được chẩn đoán giai đoạn là cT3N1MO (Kadish D). Ngoài ra, đối với người bệnh này còn xuất hiện các triệu chứng khác như đau đầu. Người bệnh thứ hai với triệu chứng chính là chảy máu cửa mũi trái, ngạt mũi trái, triệu chứng xuất hiên từng đợt trong vòng 6 tháng trước khi vào viện, với chẩn đoán giai đoạn T3NOMO (Kadish B). Chính vì các triệu chứng này xảy ra ở mũi thông thường giống với các bệnh như viêm mũi mãn tính hoăc polypoid di ứng, hay viêm xoang, nên việc chẩn đoán có thể bị trì hoãn trong thời gian dài, do đó bệnh nhân ENB thường được chẩn đoán ở giai đoạn muộn. Một trong những hệ thống phân loại ENB phổ biến là Kadish $(1976)^{4}$, với 4 giai đoạn A,B,C,D. Trường hợp người bệnh thứ nhất với Kadish $\mathrm{D}$ được mô tả khối u vượt ra ngoài khoang mũi và cạnh mũi và bao gồm sự xuất hiện của di căn hạch hoặc di căn xa của khối u. Trường hợp người bệnh thứ hai với Kadish $B$, được mô tả khối u giới hạn trong các khoang mũi và canh mũi. Các triệu chứng trên người bệnh ENB còn có sự khác nhau tùy thuộc vào vị trí xâm lấn của khối u vào các tổ chức giải phẫu lân cận. Có rất nhiều nghiên cứu về đặc điểm lâm sàng của người bệnh ENB cũng chỉ ra rằng triệu chứng ngạt mũi và chảy máu cam lần lượt chiếm tỷ lệ cao nhất. Cụ thể, nghiên cứu trên 15 người bệnh ENB giai đoạn 1994 - 2006 cho thấy 53\% người bệnh có lý do đi khám là ngạt mũi một bên, và $40 \%$ là chảy máu cam, kết quả nghiên cứu cũng chỉ ra chiếm 13/15 trường hợp tai thời điểm phát hiên bênh được chẩn đoán giai đoạn Kadish $\mathrm{B}^{5}$.

Cho đến nay, MRI và CT là hai phương thức hình ảnh chính được sử dụng để đánh giá bệnh nhân mắc ENB. Trên hình ảnh chụp $C T$, khổi u được đánh giá như là một khối mô mềm đồng nhất trong vòm mũi, với mức độ tương phản đồng đều, vừa phải. Hóa mô miễn dịch cũng có giá trị cao trong chẩn đoán ung thư nói chung, nhuộm hóa mô miễn dịch được sử dụng rộng rãi trong việc chẩn đoán các tế bào bất thường đặc biệt là trong các khối u có tính ung thư. Đối với trường hợp người bệnh thứ nhất, qua kết quả chụp CT cho thấy tổn thương dày tạo khối vùng vòm trái ngấm thuốc manh sau tiêm và lan vào xoang canh hầu trái, hiện tượng phá hủy xương thành xoang. Kết quả chụp CT kết hợp với siêu âm cho thây hình ảnh hạch cảnh cao lệch trái, hach dưới hàm trái kích thước xấp xỉ 15x10mm, và theo dõi khối hạch sau hầu. Kết quả hóa mô miễn dịch cho thông tin phù hợp với u nguyên bào thần kinh khứu giác, kết quả cụ thể các marker dương tính phù hợp như Synaptophysin, Chromogranin, CD56, NSE, và TLE1. Bệnh nhân thứ hai cho thấy hình ảnh hạch nhỏ không đặc hiệu góc hàm trái, polyp xoang bướm và có dịch ở các xoang so măt khi kết hợp chup MRI so măt với siêu âm. Kết quả xạ hình xương cho thấy có nghi ngờ tổn thương xương sọ mặt. Bệnh nhân này có tiền sử hen phế quản và viểm gan $B$ trên 10 năm, kết quả các xét nghiêm chức năng khác được chúng tôi lưu ý lại trong quá trình quyết định và theo dõi điều trị.

Phẫu thuật đã và đang là một phương pháp đóng vai trò quan trọng trong điều trị cho bệnh nhân ENB. Phương pháp điều trị kết hợp giữa phẫu thuật và xạ trị sau phẫu thuật là phác đồ điều trị phổ biến nhất cho bệnh nhân ENB ${ }^{6}$. Sự kết hợp trong điều trị này có liên quan đến tỷ lể sống sót trung bình sau điêu trị có kết quả tốt $(65 \%)$ và được thây là tốt hơn về mặt thống kê khi so sánh với tỷ lệ năm sống trung bình sau xạ trị đơn thuần? Một nghiên cứu hồi cứu về 11 người bệnh ENB điều trị giai đoạn 1982 - 2002, với phương pháp điều trị bao gồm một đợt hóa trị ban đầu, sau đó phẫu thuật cắt bỏ khối u và xạ trị sau phẫu thuật. Nhóm tác giả cũng kết luận rằng vai trò chính xác của hóa trị trong các phác đồ điều trị là không rõ ràng. Hóa trị chủ yếu dành cho những bệnh nhân có tình trạng bênh tiến triển, tái phát hoặc xuất hiện di căn. Kết quả cho thãy bệnh nhân trong nghiên cứu nêu trên có tỷ lệ sống sót sau 5 năm được theo dõi là $72 \%$. Các bác sĩ chuyên khoa ung thư tại đây cũng đã báo cáo đáp ứng với chế độ điều trị dựa trên cisplatin và khuyến nghị một phương pháp tiếp cận đa phương thức bao gồm cả hóa trị liêu ${ }^{8}$.

Hai người bênh trong nghiên cứu của chúng tôi được điều trị với pháp đồ phẫu thuật kết hợp hóa xạ đồng thời, với liều $60 \mathrm{~Gy} / 30 \mathrm{fx}$ và hóa chất Cisplatin $100 \mathrm{mg} / \mathrm{m}^{2}$ đa chu kỳ 3 tuần. Thời gian điều trị của hai người bệnh từ tháng 1/2021, đến thời điểm hiện tại 11/2021, kết quả điều trị cho thấy cả hai người bệnh đáp ứng điều trị hoàn toàn (tiêu chuẩn đánh giá đáp ứng theo 
RECIST), khối u biến mất hoàn toàn kéo dài ít nhất 4 tuần và không xuất hiện tổn thương mới. Cụ thể, kết quả CT hàm mặt trước và sau tiêm cản quang tînh mạch cho kết luận không thấy khối, hay nốt trong các xoang cạnh mũi hai bên, không có tổn thương mô mềm, không có hình ảnh hạch lớn vùng cổ hai bên. Đối với kết quả chụp MRI hàm mặt cho thây vùng mô mềm vòm họng cũng như các tuyến mang tai tuyến dưới hàm, nhu mô não vùng hố sau, hình ảnh hạch hiện tại không thấy tổn thương nghi ngờ. Ngoài ra, các kết quả chụp CT lồng ngực, ổ bụng đánh giá tình trạng di căn đều cho thấy không phát hiện tổn thương. Đặc biệt, người bệnh ENB trong nghiên cứu thông qua các thăm dò cận lâm sàng cho thấy không có ảnh hưởng trên hệ tạo huyết cũng như ngoài hệ tạo huyết. Tại thời điểm hiện tại, hai người bệnh được ghi nhận không phát hiện các biến chứng cấp trong quá trình điều trị như viêm da, viêm niêm mạc miệng, khó nuốt hoặc khô miệng.

Do nghiên cứu chỉ được tiến hành mô tả cắt ngang, báo cáo chùm ca bệnh. Vì vậy, tại nghiên cứu này chưa thể cung cấp thông tin vể số năm sống sau điều trị của người bệnh. Tuy nhiên, nhóm nghiên cứu sẽ tiếp tục tục theo dõi và cập nhật khi có kết quả chính xác. Mặc dù những phát hiện trong nghiên cứu này không mang tính đại diện hoàn toàn, nhưng kết quả này chắc chắn góp phần cung cấp dữ liệu cơ bản ban đầu để nghiên cứu sâu hơn về bệnh ENB tại Bệnh viện $\mathrm{K}$ và các bệnh viện khác tại Việt Nam.

\section{KẾT LUẬN}

Triệu chứng lâm sàng chính của 02 người bệnh ENB là chảy máu và ngạt mũi bên trái, đau đầu, kéo dài lần lượt 1 tháng, 6 tháng trước khi nhập viện. Với phác đồ điều trị phẫu thuật kết hợp hóa xạ trị đồng thời hậu phẫu với liều $60 \mathrm{~Gy} / 30 \mathrm{fx}$ và hóa chất Cisplatin $100 \mathrm{mg} / \mathrm{m}^{2}$ đa chu kỳ 3 tuần. Kết quả điều trị cho thấy người bệnh bước đầu đáp ứng hoàn toàn và không có biến chứng trên hệ tạo huyết.

\section{TÀI LIÊU THAM KHẢO}

1. Olfactory neuroblastoma - PubMed. https://pubmed.ncbi.nlm.nih.gov/20596981/

2. Kuan EC, Nasser HB, Carey RM, et al. $A$ Population-Based Analysis of Nodal Metastases in Esthesioneuroblastomas of the Sinonasal Tract. Laryngoscope. 2019;129(5):1025-1029.

3. Dulguerov $\mathbf{P}, \quad$ Calcaterra Esthesioneuroblastoma: The UCLA experience 1970-1990. The Laryngoscope. 1992;102(8):843-849.

4. Kadish S, Goodman M, Wang CC. Olfactory neuroblastoma - A clinical analysis of 17 cases. Cancer. 1976;37(3):1571-1576.

5. Esthesioneuroblastoma: Results and Outcomes of a Single Institution's Experience - PubMed. Accessed March 12, 2021. https://pubmed.ncbi.nlm.nih.gov/19721769/

6. Broich G, Pagliari A, Ottaviani F. Esthesioneuroblastoma: A general review of the cases published since the discovery of the tumour in 1924 . 1924;17(2):683-706.

7. Dulguerov $\mathbf{P}$, Allal AS, Calcaterra TC. Esthesioneuroblastoma: a meta-analysis and review. 2001;2(11):683-690.

8. El Kababri M, Habrand JL, Valteau-Couanet D, Gaspar N, Dufour C, Oberlin 0 . Esthesioneuroblastoma in Children and Adolescent: Experience on 11 Cases with Literature Review. Journal of Pediatric Hematology/Oncology. 2014;36(2):91-95.

\section{MộT SỐ YẾU TỐ LIÊN QUAN TỚI KIẾN THỨC TỰ CHĂM SÓC CỦA NGƯỜI BÊNH ĐÁI THÁO ĐƯỜNG TYPE 2 ĐIỀU TRI NGOẠI TRÚ TẠI BỆNH VIÊ̂N XÂY DỰNG TRONG THỜI KỲ COVID 19}

\section{TÓM TẮT}

Mục tiêu: Mô tả thực trạng và các yếu tố liên quan đến kiến thức tự chăm sóc của ngưới bênh đái tháo đường type 2 điều trị ngoại trú tại Bệnh viện Xây

\footnotetext{
${ }^{1}$ Trường Đại học Y Hà Nội

²Bênh viện Xây dựng

Chịu trách nhiệm chính: Trần Thị Thanh Hương

Email: huongtran2008@gmail.com

Ngày nhận bài: 13.9.2021

Ngày phản biên khoa hoc: 10.11.2021

Ngày duyệt bài: 17.11.2021
}

\section{Trần Thị Thanh Hương ${ }^{1}$, Lê Việt Hạnh ${ }^{2}$} dựng thời kỳ Covid 19. Đối tượng và phương pháp nghiên cứu: Nghiễn cứu mô tả cắt ngang, đã được thực hiện với cỡ mẫu 300 người bệnh đái tháo đường type 2 đáp ứng tiêu chuẩn phỏng vấn bằng bộ câu hỏi chuẩn bi trước. Kết quả: Tỷ lể người bểnh chưa có kiến thức tốt về tự chăm sóc chiếm $40,3 \%$, với điểm trung bình của các nôi dung về tự chăm sóc đat 20,25 $\pm 3,49$ trên tổng điểm 30, trong đó chủ yếu là thiếu kiến thức về kiếm soát đường máu. Nghiên cứu của chúng tôi đã tìm ra mối liên quan giữa kiến thức với trình độ học vấn; thời gian mắc bệnh; thuốc điều trị đái tháo đường. Kết luận: Kiến thức tự chăm sóc của người bệnh đái tháo đường type 2 còn hạn chế. 